\title{
Pterostilbene modulates the suppression of multidrug resistance protein 1 and triggers autophagic and apoptotic mechanisms in cisplatin-resistant human oral cancer CAR cells via AKT signaling
}

\author{
HUI-PING CHANG ${ }^{1 *}$, CHI-CHENG LU $^{2 *}$, JO-HUA CHIANG ${ }^{3}$, FUU-JEN TSAI $^{4-6}$, \\ YU-NING JUAN $^{7}$, JE-WEI TSAO ${ }^{8}$, HONG-YI CHIU ${ }^{2}$ and JAI-SING YANG ${ }^{7}$
}

\begin{abstract}
${ }^{1}$ Department of Traditional Chinese Medicine, Tainan Municipal Hospital (Managed by Show Chwan Medical Care Corporation), Tainan 701; ${ }^{2}$ Department of Pharmacy, Buddhist Tzu Chi General Hospital, Hualien 970; ${ }^{3}$ Department of Nursing, Chung Jen Catholic Junior College, Chiayi 622; ${ }^{4}$ Human Genetics Center, Department of Medical Research, China Medical University Hospital; ${ }^{5}$ School of Chinese Medicine, China Medical University; Departments of ${ }^{6}$ Medical Genetics and ${ }^{7}$ Medical Research, China Medical University Hospital, China Medical University; ${ }^{8}$ School of Pharmacy, China Medical University, Taichung 404, Taiwan, R.O.C.
\end{abstract}

Received November 13, 2017; Accepted February 20, 2018

DOI: $10.3892 /$ ijo. 2018.4298

\begin{abstract}
Pterostilbene is a natural polyphenolic compound that is primarily found in fruits, such as blueberries and has a similar structure to resveratrol. Pterostilbene exhibits antioxidant, anti-inflammatory and antitumor activity but the effects of pterostilbene on drug-resistant oral cancer cells and its underlying mechanisms of action have not yet been explored. Therefore, the present study was performed to clarify the anticancer effects of pterostilbene on cisplatin-resistant human oral cancer CAR cells. The results demonstrated that CAR cells exhibited marked shrinkage, cell membrane breakage and autophagic vacuole formation following treatment with pterostilbene. Pterostilbene also effectively inhibited cell viability and suppressed cell confluence in a time- and concentration-dependent manner. Probing with acridine orange, monodansylcadaverine and LysoTracker Red demonstrated that the number of acidic vesicular organelles was increased, indicating increased autophagy. Furthermore, Heochst 33342 staining determined that DNA condensation, a characteristic of apoptosis, was enhanced following treatment with pterostilbene. Furthermore, pterostilbene upregulated mRNA levels of $L C 3-I I$ and Atg12, as well as the expression of Atgs/Beclin-1/LC3-associated signaling, suggesting that it enhances autophagy. The autophagy inhibi-
\end{abstract}

Correspondence to: Dr Jai-Sing Yang, Department of Medical Research, China Medical University Hospital, China Medical University, 2 Yude Road, Taichung 40447, Taiwan, R.O.C.

E-mail: jaisingyang@gmail.com

*Contributed equally

Key words: pterostilbene, autophagy, apoptosis, multidrug resistance protein 1, protein kinase B, cisplatin-resistant oral cancer cells tors 3-methyladenine and chloroquine were used to confirm that pterostilbene induces autophagy. It was also determined that pterostilbene triggered caspase-dependent apoptosis by directly testing DNA breakage and using the pan-caspase inhibitor carbobenzoxyvalyl-alanyl-aspartyl fluoromethyl ketone. The results demonstrated that pterostilbene mediates the apoptosis of CAR cells via the intrinsic apoptotic cascade. In addition, pterostilbene inhibited MDR1 expression and the phosphorylation of AKT on the Ser473 site in CAR cells. Therefore, pterostilbene may elicit an oral anticancer response in drug-resistant cells and may be used as a chemotherapeutic adjuvant to treat patients with oral cancer.

\section{Introduction}

Cancer of the oral cavity is one of the leading causes of cancer-associated mortality in Taiwan; patients with oral cancer generally have a poor prognosis and experience high rates of mortality $(1,2)$. In Taiwan, oral cancer is the fifth leading cause of cancer-associated mortality, according to the 2016 annual report by the Ministry of Health and Welfare (Taiwan, R.O.C.) (3). The primary risk factors for oral cancer are betel nut chewing, smoking, alcohol consumption, human papillomavirus infection, and cell inflammation $(1,4)$. Surgery, radiation therapy, and chemotherapeutic drugs are currently the preferred methods of treating oral cancer $(4,5)$. Cisplatin, carboplatin, 5-fluorouracil, paclitaxel and docetaxel are the chemotherapeutic agents currently used to treat patients with oral cancer (6-9); however, they do not significantly improve survival rates. Furthermore, the development of resistance to chemotherapeutic reagents is a serious clinical issue $(10,11)$; therefore, novel and safe chemotherapeutic agents are required for the effective treatment of oral cancer.

Natural products and phytochemicals found in plants commonly used in Traditional Chinese Medicine have been investigated for their possible efficacy against different types of cancer. Some have exhibited anticancer activity and 
low toxicity such that they may be potential candidates for treatment $(12,13)$. Stilbenes are a class of natural polyphenolic compounds found in peanuts, berries, grapes, and red wine (13). Pterostilbene (trans-3,5-dimethoxy-4-hydroxystilbene) is a stillbene that is a structural derivative of resveratrol and is found in blueberries, grapes, tree wood and Pterocarpus marsupium $(14,15)$. The pharmacological activities of pterostilbene mean that it may be used treat different types of diseases, including cancer, diabetes, inflammation and dyslipidemia (13-17). Studies have also indicated that pterostilbene may exhibit anticancer activity against various types of cancer, including breast $(18,19)$, pancreatic $(20,21)$, lung $(22-24)$, prostate $(25,26)$, colorectal $(27-29)$, bladder (30), gastric (31) and oral cancer (32-34), as well as hepatocellular carcinoma $(35,36)$ and leukemia (37-40). The results of in vitro and in vivo studies have demonstrated that pterostilbene induces apoptotic and/or autophagic cell death $(29,32,41,42)$. Pterostilbene may induce autophagy and apoptosis by modulating the activities of protein kinase $\mathrm{B}$ (AKT) and mitogen-activated protein kinase in oral cancer SAS and OECM-1 cells (32). Furthermore, pterostilbene inhibits the migration and invasion of SAS and OECM-1 cells by suppressing the activity and expression of matrix metalloproteinase 2 (34). However, to the best of our knowledge, the effects of pterostilbene on cisplatin-resistant oral cancer have not yet been evaluated. The present study aimed to investigate the potential anti-proliferative effects of pterostilbene and the mechanisms by which it induces cell death and suppresses multidrug resistance protein 1 (MDR1) expression in cisplatin-resistant human oral cancer CAR cells.

\section{Materials and methods}

Reagents. Dulbecco's modified Eagle's medium (DMEM), fetal bovine serum (FBS), L-glutamine and penicillin/streptomycin were purchased from HyClone; GE Healthcare Life Sciences (Logan, UT, USA). Acridine orange (AO), Hoechst 33342 , LysoTracker Red DND-99, trypsin-EDTA, the High Capacity cDNA Reverse Transcription kit, Pierce bicinchoninic acid (BCA) protein assay kit and SYBR-Green PCR Master mix were sourced from Thermo Fisher Scientific, Inc. (Waltham, MA, USA). The Immobilon-P polyvinylidene difluoride transfer membrane and Immobilon western chemiluminescent horseradish peroxidase (HRP) substrate were purchased from EMD Millipore (Billerica, MA, USA). Caspase-3 (cat. no. K106-100), -8 (cat. no. K113-100), and -9 (cat. no. K119-100) colorimetric assay kits were obtained from R\&D Systems, Inc. (Minneapolis, MN, USA). All primary antibodies, as well as anti-mouse and anti-rabbit immunoglobulin (Ig)G HRP-linked secondary antibodies were all procured from GeneTex International Corporation (Hsinchu, Taiwan). Pterostilbene, 3-methyladenine (3-MA), chloroquine (CQ), carbobenzoxyvalyl-alanyl-aspartyl fluoromethyl ketone (Z-VAD-FMK), monodansylcadaverin (MDC) and all other chemicals and reagents were obtained from Sigma-Aldrich; Merck KGaA (Darmstadt, Germany), unless otherwise specified.

Cell culture. Cisplatin-resistant human oral cancer CAR cells were established from the human oral cancer cell line CAL 27 (American Type Culture Collection, Manassas, VA, USA) following a previously reported method $(43,44)$. CAR cells were then cultured in DMEM containing 10\% FBS, $1 \%$ penicillin/streptomycin $(100 \mu \mathrm{g} / \mathrm{ml}$ streptomycin and $100 \mathrm{U} / \mathrm{ml}$ penicillin), $2 \mathrm{mM}$ L-glutamine and $80 \mu \mathrm{M}$ cisplatin. Cells were maintained at $37^{\circ} \mathrm{C}$ in a $5 \% \mathrm{CO}_{2} / 95 \%$ air humidified incubator. Prior to administration, pterostilbene was dissolved in dimethyl sulfoxide (DMSO) and the final concentration of DMSO was $<0.5 \%$. Control cells were exposed to $0.5 \%$ DMSO alone.

Cell viability assay and morphological determination. CAR cells were seeded onto 96-well culture plates at a density of $1 \times 10^{4}$ cells/well (100 $\mu \mathrm{l} /$ well $)$ and subsequently incubated with $5,10,25,50,75$ and $100 \mu \mathrm{M}$ pterostilbene for 24,48 and $72 \mathrm{~h}$. The effect of pterostilbene on cell viability was then determined using an MTT assay, as previously described $(45,46)$. For the inhibition assays, cells were pretreated with autophagy inhibitors (10 mM 3-MA and $20 \mu \mathrm{M}$ CQ) and $15 \mu \mathrm{M}$ Z-VAD-FMK (a pan-caspase inhibitor) for $1 \mathrm{~h}$ prior to exposure to 50 or $75 \mu \mathrm{M}$ pterostilbene for 24 or $48 \mathrm{~h}$. Following the exposure of cells to pterostilbene, MTT $(5 \mathrm{mg} / \mathrm{ml})$ was dissolved in phosphate-buffered saline, and $10 \mu \mathrm{l} \mathrm{MTT}$ solution was added to each well at a final concentration of $500 \mu \mathrm{g} / \mathrm{ml}$ for $2 \mathrm{~h}$. The blue formazan crystals were then dissolved in DMSO (100 $\mu \mathrm{l} /$ well) by constant shaking for $10 \mathrm{~min}$. The absorbance of each well was measured using an enzyme-linked immunosorbent assay (ELISA) plate reader at a test wavelength of $570 \mathrm{~nm}$, with a reference wavelength of $620 \mathrm{~nm}$. Half maximal inhibitory concentrations $\left(\mathrm{IC}_{50}\right)$ were calculated using the improved Karber method, using the following formula: $\left(\lg \mathrm{IC}_{50}=\mathrm{Xm}-\mathrm{I}[\mathrm{P}-(3-\mathrm{Pm}-\mathrm{Pn}) / 4]\right.$, where $\mathrm{Xm}, \lg$ (maximum dose); I, $\lg$ (maximum dose/adjacent dose); $\mathrm{P}$, sum of the positive reaction rates; $\mathrm{Pm}$, maximum positive reaction rate; and $\mathrm{Pn}$, minimum positive reaction rate (47). For the examination of cell morphology, cells were observed without any treatments (control), observed following treatment with pterostilbene alone, treatment with the autophagy inhibitors (10 mM 3-MA or $20 \mu \mathrm{M} \mathrm{CQ}$ ) alone, and following treatment with pterostilbene and each of the autophagy inhibitors. Cells were incubated and subsequently observed and photographed using a phase-contrast microscope at a magnification of $x 400$.

Dynamic cell confluence assay. CAR cells ( $1 \times 10^{4}$ cells/well) were seeded onto a 96-well plate and treated with $0,25,50$, 75 or $100 \mu \mathrm{M}$ pterostilbene. The cell confluence experiment was conducted over $48 \mathrm{~h}$ with data collection every $2 \mathrm{~h}$ and was monitored using the IncuCyte ZOOM System instrument (Essen BioScience, Ann Arbor, MI, USA), as previously described $(48,49)$.

Autophagy assays and Hoechst 33342 staining. CAR cells were plated onto sterile chamber slides onto $10-\mathrm{cm}$ tissue culture dishes at a density of $1 \times 10^{6}$ cells/plate. Cells were treated with $0,25,50$ or $75 \mu \mathrm{M}$ pterostilbene for $24 \mathrm{~h}$ following pretreatment with or without $10 \mathrm{mM} 3-\mathrm{MA}$ or $20 \mu \mathrm{M}$ CQ for $1 \mathrm{~h}$. Cells were then fixed with $4 \%$ paraformaldehyde on ice for $15 \mathrm{~min}$ and were individually probed with either $1 \mu \mathrm{g} / \mathrm{ml} \mathrm{AO,} 100 \mu \mathrm{M}$ MDC, $1 \mu \mathrm{g} / \mathrm{ml}$ LysoTracker Red or $1 \mu \mathrm{g} / \mathrm{ml}$ Hoechst 33342 for $15 \mathrm{~min}$ at room temperature, as previously described $(50,51)$. Lysosomal activity in the pterostilbene-treated cells were 
determined using the Magic Red Cathepsin B assay kit (ImmunoChemistry Technologies, LLC, Bloomington, MN, USA) following the manufacturer's protocol. Following staining, each slide was mounted with coverslips, and photomicrographs of acidic vesicular organelles (AVOs), autophagic vacuoles, lysosomal biogenesis, and nuclei were taken using a fluorescence microscope.

Reverse transcription-quantitative polymerase chain reaction $(R T-q P C R)$. CAR cells $\left(5 \times 10^{6}\right)$ in T75 flasks were treated with 0 , 50 and $75 \mu \mathrm{M}$ pterostilbene for $24 \mathrm{~h}$. Total RNA was then isolated using QIAGEN RNeasy Mini kit (Qiagen, Inc., Valencia, CA, USA), according to the manufacturer's instructions and cDNA synthesis was completed using the High Capacity cDNA Reverse Transcription kit. qPCR was performed under the following conditions: $10 \mathrm{~min}$ at $95^{\circ} \mathrm{C}, 40$ cycles of $15 \mathrm{sec}$ at $95^{\circ} \mathrm{C}$ and $1 \mathrm{~min}$ at $60^{\circ} \mathrm{C}$. qPCR was performed using 2X SYBR-Green PCR Master mix and $200 \mathrm{nM}$ forward and reverse primers for light chain 3 (LC3)-II, autophagy-related gene (Atg)12 and MDR1. GAPDH was used as a reference gene. The sequences of the primers used were as follows: LC3-II, forward, 5'-CCGACCGCTGTAAGGAGGTA-3' and reverse, 5'-AGGACGGGCAGCTGCTT-3'; Atg12, forward, 5'-TGTGGCCTCAGAACAGTTGTTTA-3' and reverse, 5'-CGC CTGAGACTTGCAGTAATGT-3'; MDR1, forward, 5'-GTG TGGTGAGTCAGGAACCTGTAT-3' and reverse, 5'-TCTCAA TCTCATCCATGGTGACA-3'; GAPDH, forward, 5'-ACACCC ACTCCTCCACCTTT-3' and reverse, 5'-TAGCCAAATTCG TTGTCATACC-3'. Each assay was run on an Applied Biosystems 7300 Real-Time PCR System (Applied Biosystems; Thermo Fisher Scientific, Inc.) in triplicate, and the fold-changes of gene expression were derived using the comparative $2^{-\Delta \Delta \mathrm{Cq}}$ method, as previously described $(50,52)$.

Western blot analysis. CAR cells at a density of $5 \times 10^{6}$ cells per 75T flask were incubated with 0,50 and $75 \mu \mathrm{M}$ pterostilbene for 24 or $48 \mathrm{~h}$. Cell samples were lysed in the Trident RIPA Lysis Buffer (cat. no. GTX400005; GeneTex) and collected as previously described $(53,54)$. Protein concentration was determined using the Pierce BCA protein assay kit. Equal amounts of the protein sample $(40 \mu \mathrm{g})$ were prepared and subsequently 10-12\% SDS-PAGE was performed. Proteins were transferred to the Immobilon-P polyvinylidene difluoride transfer membrane prior to blocking with Trident Universal Protein Blocking Reagent (cat. no. GTX30963; GeneTex) for $1 \mathrm{~h}$ at room temperature. The membrane was subsequently incubated with primary antibodies against Atg5 (cat. no. GTX113309), Atg7 (cat. no. GTX113613), Atg12 (cat. no. GTX629815), Beclin-1 (cat. no. GTX631396), LC3 (cat. no. GTX39752; LC3-I, 17 kDa; LC3-II, 14 kDa), Bcl-2 (cat. no. GTX100064), Bax (cat. no. GTX109683), cytochrome $c$ (cat. no. GTX108585), caspase-9 (cat. no. GTX112888; active form, $19 \mathrm{kDa}$ ), caspase-3 (cat. no. GTX110543; active form, $19 \mathrm{kDa}$ ), caspase-7 (cat. no. GTX22301; active form, $20 \mathrm{kDa}$ ), poly (ADP-ribose) polymerase (PARP; cat. no. GTX100573; p85, 85 kDa), MDR1 (cat. no. GTX108370), phosphorylated (p)-AKT (Ser473) (cat. no. GTX28932), AKT (cat.no. GTX121937) and $\beta$-actin (cat. no. GTX109639) at $4^{\circ} \mathrm{C}$ overnight. All antibodies were purchased from GeneTex and used at a dilution of at 1:1,000. Membranes were then incu- bated with appropriate anti-mouse (cat. no. GTX213111-01) and anti-rabbit (cat. no. GTX213110-01) IgG HRP-linked secondary antibodies at a dilution of 1:10,000 for $1 \mathrm{~h}$ at room temperature. Blot visualization was performed using the Immobilon Western Chemiluminescent HRP Substrate and all bands of immunoblots were normalized to the densitometric value of $\beta$-actin. The bands were quantified by densitometry using ImageJ software version 1.41 (National Institutes of Health, Bethesda, MA, USA).

Quantification of cellular apoptosis and DNA breaks. CAR cells $\left(1 \times 10^{5}\right.$ cells $\left./ \mathrm{ml}\right)$ on 12 -well plates were harvested following treatment with $0,25,50,75$ and $100 \mu \mathrm{M}$ pterostilbene for $48 \mathrm{~h}$ and re-suspended with the In Situ Cell Death Detection kit, Fluorescein (Sigma-Aldrich; Merck KGaA) to perform terminal deoxynucleotidyl transferase-mediated d-UTP nick end labeling (TUNEL), following the manufacturer's protocol. TUNEL-positive cells were then assessed using a BD FACSCalibur Flow Cytometer (BD Biosciences, San Jose, CA, USA) and the data were quantified using the BD CellQuest Pro Software version 5.1 (BD Biosciences), as previously described (55).

Assessment of caspase -3 and -9 activity via colorimetric

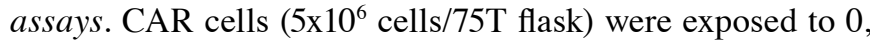
$25,50,75$ and $100 \mu \mathrm{M}$ pterostilbene for $48 \mathrm{~h}$. Cell lysates were harvested and the activities of caspases- 3 and -9 were then measured using the caspase- 3 and -9 colorimetric assay kits, following the manufacturer's protocol.

Statistical analysis. All results are expressed as the mean \pm standard deviation of triplicate samples. Statistical analysis was performed using SPSS software version 16.0 (SPSS, Inc., Chicago, IL, USA). Differences among groups were determined using one-way analysis of variance followed by Dunnett's test. $\mathrm{P}<0.05$ was considered to indicate a statistically significant difference.

\section{Results}

Pterostilbene induces cytotoxicity in cisplatin-resistant human oral cancer CAR cells. Following treatment with different concentrations $(5,10,25,50,75$ and $100 \mu \mathrm{M})$ of pterostilbene for 24,48 and $72 \mathrm{~h}$, cells underwent apoptotic changes, including cell shrinkage, membrane blebbing and rounding and acquire autophagic characteristics (Fig. 1A). Furthermore, pterostilbene treatment decreased the number of CAR cells compared with the untreated control, as recorded by a phase-contrast microscope. These effects occurred in a timeand concertation-dependent manner (Fig. 1A). Furthermore, incubation with pterostilbene for 24,48 and $72 \mathrm{~h}$ significantly decreased cell viability in a time- and concentration-dependent manner (Fig. 1B). The $\mathrm{IC}_{50}$ values of pterostilbene in CAR cells following 24,48 and $72 \mathrm{~h}$ incubation were $78.26 \pm 4.33$, $48.04 \pm 3.68$ and $20.65 \pm 4.88 \mu \mathrm{M}$, respectively. Interestingly, administration of $0,25,50,75$ and $100 \mu \mathrm{M}$ pterostilbene suppressed cell confluence over a 48 -h period in a time- and concentration-dependent manner (Fig. 2 and supplementary data: https://youtu.be/P7MCMTJnO00). Thus, pterostilbene may induce CAR cell death via autophagy and apoptosis. 


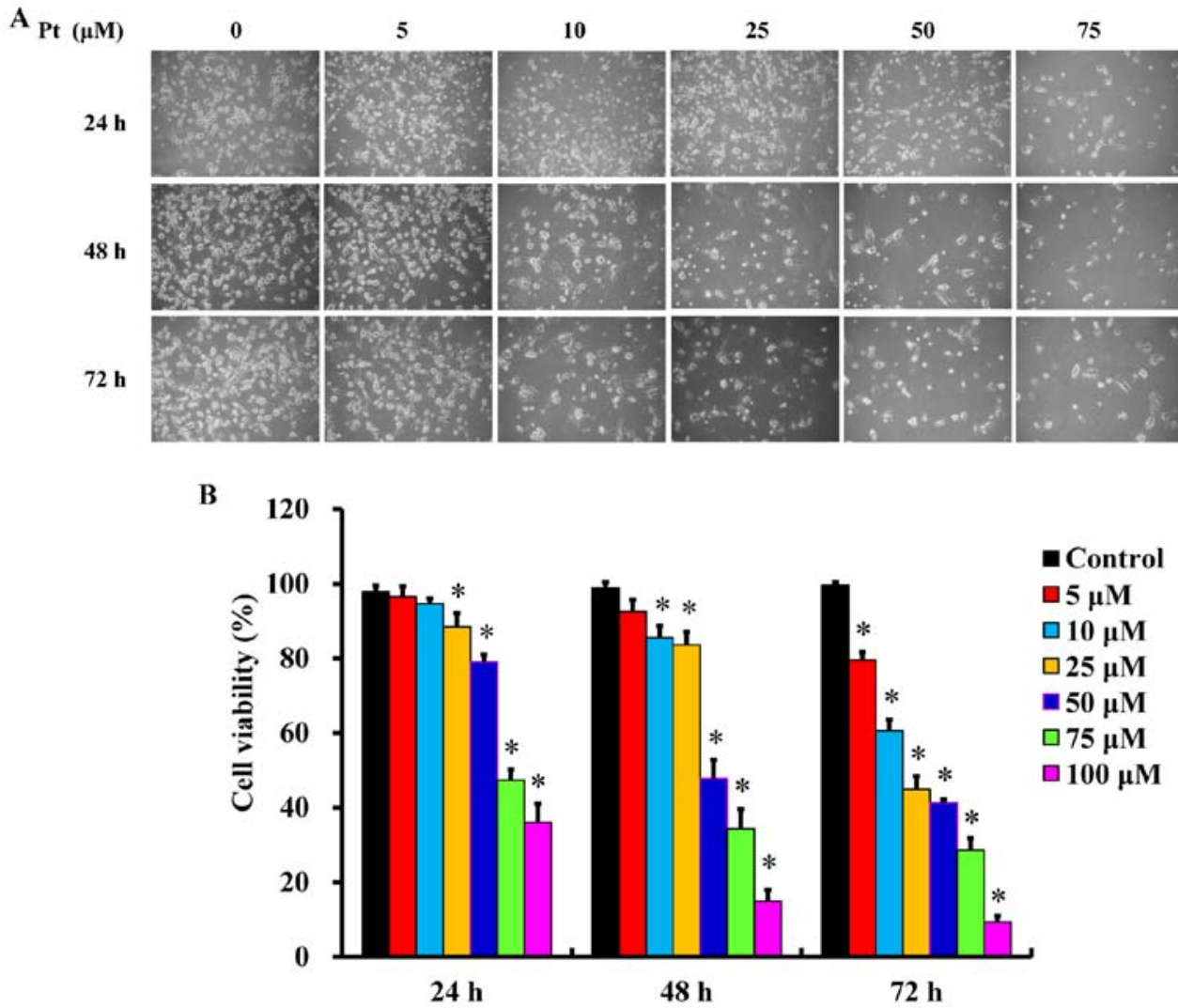

Figure 1. Effects of pterostilbene on the morphology and viability of CAR cells. Cells were exposed to 5, 10,25, 50,75 and $100 \mu \mathrm{M}$ Pt for 24,48 and $72 \mathrm{~h}$. (A) Cells were photographed using a phase-contrast microscope and the representative images are one of three separate images (magnification, x200). (B) The viability of CAR cells as determined by the MTT assay. Values are presented as the mean \pm standard deviation of three independent experiments. "P $<0.05$ vs. untreated control. Pt, pterostilbene.

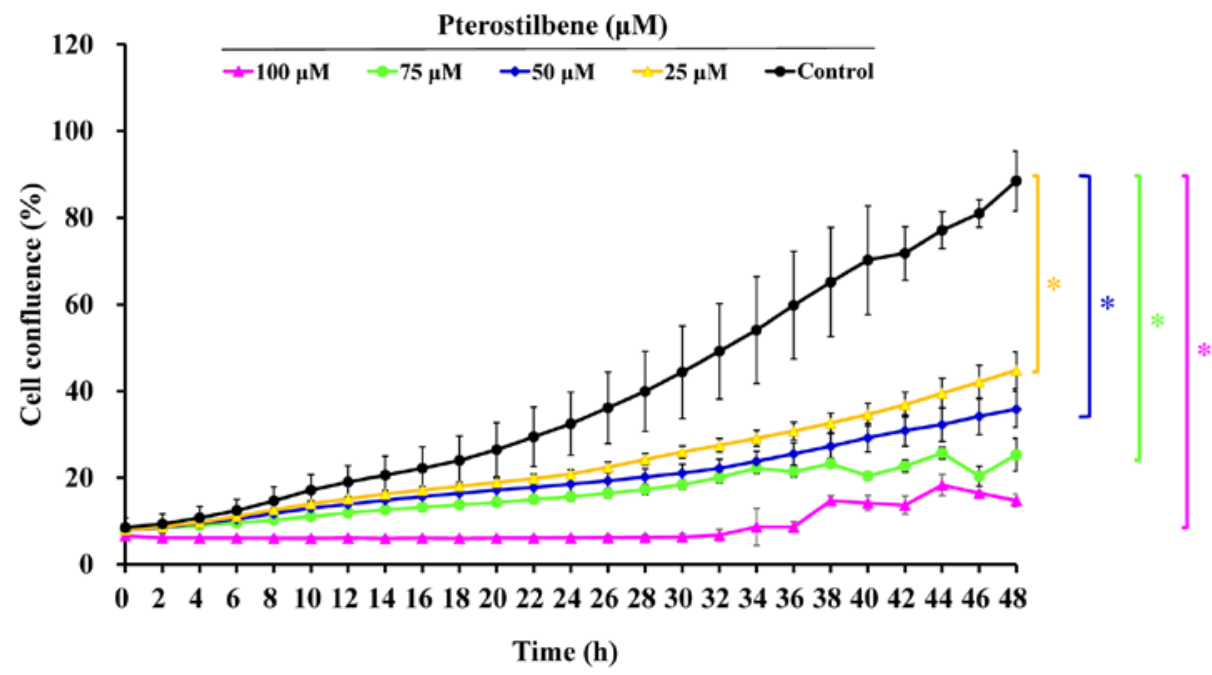

Figure 2. Effects of pterostilbene on CAR cell confluence. Cells were incubated with 25, 50, 75 and $100 \mu \mathrm{M}$ pterostilbene over a 48-h period, and cell confluence was measured every $2 \mathrm{~h}$. Cell confluence was determined and analyzed using the IncuCyte ZOOM System instrument at $2 \mathrm{~h}$ intervals over the 48 -h period Values represent the mean \pm standard deviations of three independent experiments. ${ }^{*} \mathrm{P}<0.05$ vs. untreated control.

Pterostilbene triggers the autophagy and apoptosis of CAR cells. To determine whether autophagic cell death is caused by pterostilbene, AVOs, autophagosome vesicles or lysosome activity were detected using different molecular probes, including AO, MDC, LysoTracker Red and cathepsin B. AO and MDC staining indicated that pterostilbene markedly increased the number of AVOs within the cytoplasm compared with the untreated control (Fig. 3A and B). LysoTracker Red and cathepsin B staining also indicated that treatment with pterostilbene caused the accumulation of autophagic vacuole marker and suppressed lysosome activity (Fig. 3C and D). In addition, increased DNA condensation occurred in cells treated with 25,50 and $75 \mu \mathrm{M}$ pterostilbene for $24 \mathrm{~h}$, as indicated by Hoechst 33342 staining (Fig. 3E). These results demonstrate 


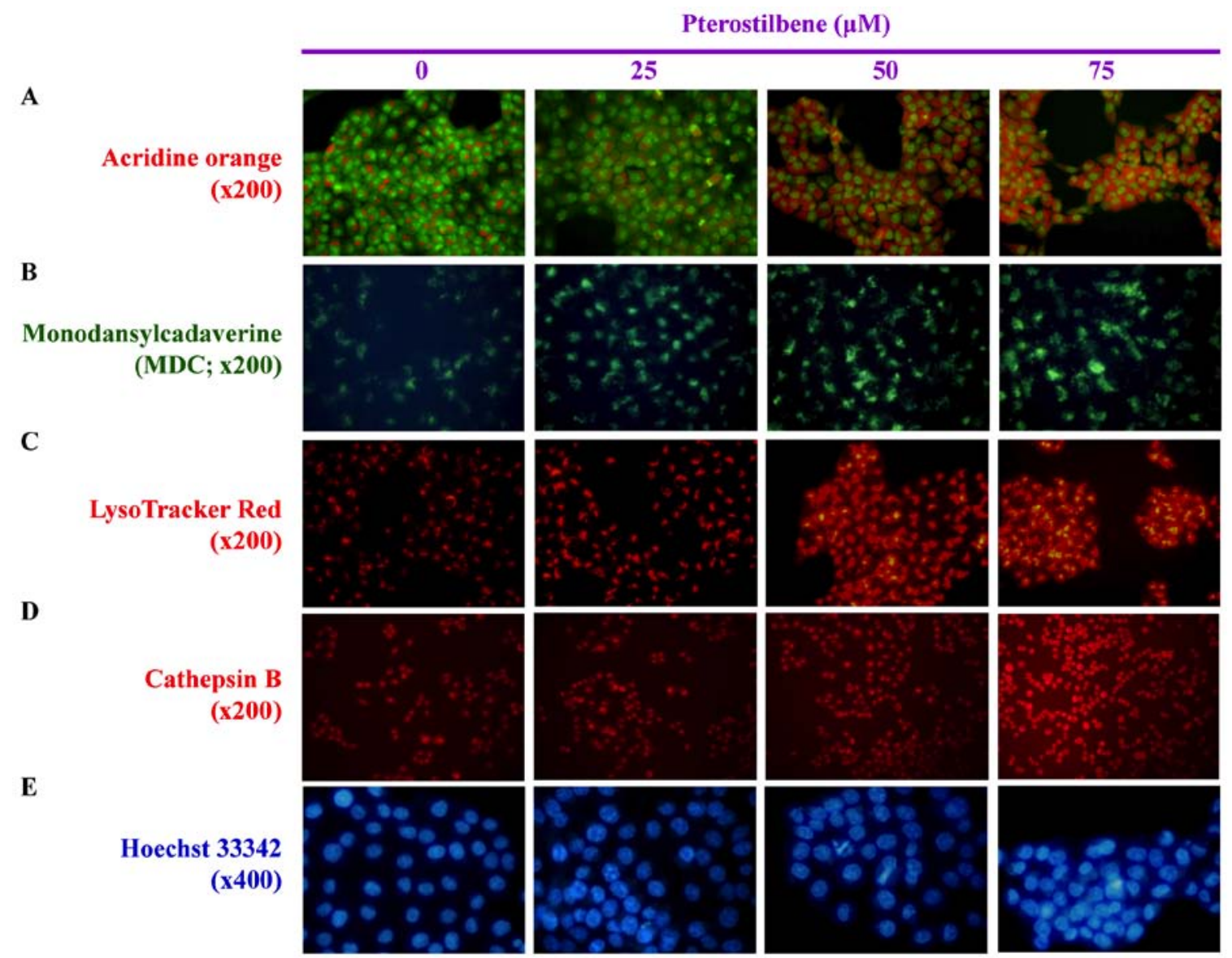

Figure 3. Effects of pterostilbene on the autophagy and DNA condensation of CAR cells. The cells were treated with $0,25,50$ and $75 \mu \mathrm{M}$ pterostilbene for $24 \mathrm{~h}$ and then probed using (A) acridine orange to detect acidic vesicular organelles, indicated by a red color (magnification, x200). (B) Monodansylcadaverin, an autophagolysosome marker, indicated by a green color (magnification, x200). (C) LysoTracker Red to determine lysosomal function, indicated by a red color (magnification, x200). (D) Cathepsin B to detect lysosomal activity, indicated by a red color (magnification, x200). (E) Hoechst 33342 staining to observe cell nuclei, as indicated by a blue color (magnification, $\mathrm{x} 400$ ). Representative images were taken from three independent experiments.

that pterostilbene-elicited CAR cell death is mediated by autophagic and apoptotic responses.

Pterostilbene induces the expression of autophagy-associated genes and stimulates its signaling in CAR cells. To further investigate the effect of pterostilbene on autophagy, the gene and protein levels of key autophagic regulators, including Atg5, Atg7, Atg12, Beclin-1 and LC3 were assessed using RT-qPCR analysis and western blotting. Following treatment of cells with 50 and $75 \mu \mathrm{M}$ pterostilbene for $24 \mathrm{~h}$, there was a significant increase in the mRNA expression of LC3-II (Fig. 4A) and Atg12 (Fig. 4B). Treatment with 50 and $75 \mu \mathrm{M}$ pterostilbene also markedly increased the protein expression of Atg5, Atg7, Atg12, Beclin-1 and LC3-II in CAR cells. These results imply that pterostilbene provokes the autophagy of CAR cells by increasing the expression of Atg/Beclin-1/LC3-associated molecules.

The autophagy inhibitors 3-MA and $C Q$ reverse the decrease in CAR cell viability induced by pterostilbene. Cells were pretreated with $10 \mathrm{mM} 3-\mathrm{MA}$ or $20 \mu \mathrm{M}$ CQ and subsequently exposed to $75 \mu \mathrm{M}$ pterostilbene for $24 \mathrm{~h}$. Cell viability, autophagic characteristics and AVOs were individually monitored using an MTT assay, microscopic examination of cell morphology and staining with $\mathrm{AO}$, followed by fluorescence microscopy. The results demonstrated that 3-MA and CQ significantly increased the viability of CAR cells following pterostilbene treatment, compared with cells treated with pterostilbene alone (Fig. 5A). Similarly, pretreatment of CAR cells with 3-MA and CQ suppressed the development of autophagic characteristics (Fig. 5B) and AVOs (Fig. 5C) following exposure to pterostilbene. These results suggest that pterostilbene-induced autophagy in CAR cells may be mediated by phosphatidylinositol-4,5-bisphosphate 3-kinase class III signaling.

Pterostilbene induces the apoptosis of CAR cells via a caspasedependent pathway. The effects of pterostilbene on cell apoptosis and its underlying mechanism of action was subsequently assessed. Following treatment with 25, 50, 75 and $100 \mu \mathrm{M}$ pterostilbene for $48 \mathrm{~h}$, cells were detected for DNA breaks and direct apoptotic responses. Pterostilbene significantly increased the number of TUNEL-positive cells in a concentration-dependent manner (Fig. 6A), indicating that it induces apoptosis. To determine if the caspase cascade contributes to this pterostilbene-induced apoptosis, the pan-caspase inhibitor Z-VAD-FMK was used to pretreat CAR cells prior to incubation with $50 \mu \mathrm{M}$ pterostilbene. Z-VAD-FMK significantly reversed the viability of cells treated with pterostilbene alone, by $32.6 \%$ (Fig. 6B). These results indicate that pterostilbene induces the apoptosis of CAR cells via caspase-dependent signaling. 

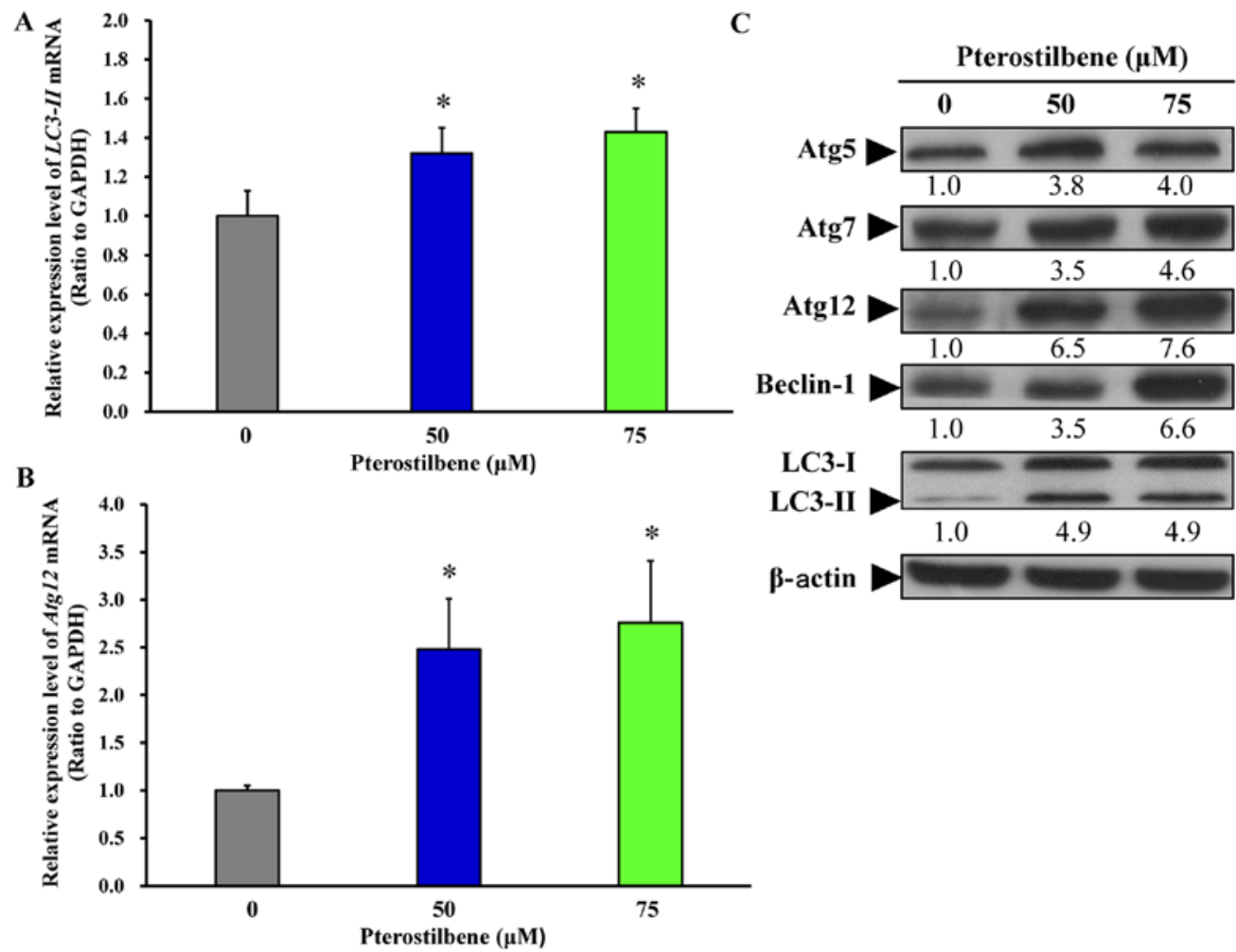

Figure 4. Effects of pterostilbene on autophagy-associated signals of CAR cells. Cells were treated with 0,50 and $75 \mu \mathrm{M}$ pterostilbene for $24 \mathrm{~h}$, and then total RNA and protein were individually prepared. Reverse transcription-quantitative polymerase chain reaction was performed to measure (A) LC3-II and (B) Atg12 mRNA expression. Values represent the mean \pm standard deviation of three independent experiments. "P<0.05 vs. untreated control. (C) Representative blots of Atg5, Atg7, Atg12, Beclin-1 and LC3, as detected by western blotting. Representative images were taken from three independent experiments. LC3, light chain 3; Atg, autophagy related gene.

The mitochondria-dependent pathway contributes to pterostilbene-induced apoptosis in CAR cells. Following the determination of the apoptosis-inducing effect of pterostilbene on molecular signals, its underlying mechanism of action was further investigated. Treatment with 50, 75 and $100 \mu \mathrm{M}$ pterostilbene for $48 \mathrm{~h}$ significantly increased caspase-3 (Fig. 7A) and caspase-9 (Fig. 7B) activity in a concentration-dependent manner, compared with untreated control cells. Furthermore, there was no significant increase in caspase- 8 activity (data not shown) following pterostilbene treatment. To determine changes in the expression of mitochondria-modulated pro- and anti-apoptotic proteins, levels of these proteins in pterostilbene-treated cells were measured. The results demonstrated that 50 and $75 \mu \mathrm{M}$ pterostilbene upregulated the expression of Bax, cytochrome $c$, the active forms of caspase-9, caspase-3, caspase-7 and PARP, but it downregulated the expression of Bcl-2 (Fig. 7C). These results indicate that pterostilbene induces CAR cell death by activating the intrinsic (caspase-9and caspase-3-dependent) apoptotic cascade.

Pterostilbene suppresses the expression of MDR1 and AKT signaling in CAR cells. Following treatment with 50 and $75 \mu \mathrm{M}$ pterostilbene for $24 \mathrm{~h}$, the mRNA and protein expression of MDR1 was monitored. Pterostilbene treatment significantly decreased the expression of MDR1 mRNA (Fig. 8A) and protein (Fig. 8B). Furthermore, treatment with 50 and $75 \mu \mathrm{M}$ pterostilbene decreased the phosphorylation of AKT on the Ser473 site but had no effect on total AKT protein expression (Fig. 8B). Collectively, these results indicate that pterostilbene triggers the autophagy and apoptosis of CAR cells by suppressing MDR1 expression and AKT signaling. The proposed schematic representation of the plausible molecular signaling induced by pterostilbene in CAR cells is summarized in Fig. 9.

\section{Discussion}

A previous study by our group indicated that resveratrol induces autophagy and apoptosis by modulating AMP-activated protein kinase and AKT/mechanistic target of rapamycin signaling in cisplatin-resistant human oral cancer CAR cells (51). To the best of our knowledge, the present study is the first to report that pterostilbene triggers the autophagy and apoptosis of CAR cells, as well as the first to indicate that pterostilbene suppresses MDR1 expression. Pterostilbene and resveratrol exhibit similar anticancer and biological activities; however, pterostilbene is more effective: i) Pterostilbene contains two methoxy groups and one hydroxyl group, whereas resveratrol contains three hydroxyl groups. Therefore, pterostilbene has more lipophilic properties than resveratrol, as the two methoxy groups that it contains that serve to increase oral absorption and cellular uptake $(56,57)$. ii) Pharmacokinetic analysis indicates that pterostilbene has $95 \%$ bioavailability however resveratrol only has $20 \%$ when administered orally $(58,59)$. iii) The half-life of pterostilbene is $93.9 \pm 22.3 \mathrm{~min}$ in Sprague-Dawley rats (60), while that of resveratrol is $14 \mathrm{~min}$ in rabbits (61). Furthermore, the $\mathrm{IC}_{50}$ values of resveratrol in CAR cells following 24, 48 and $72 \mathrm{~h}$ exposure were $95.23 \pm 3.26,73.23 \pm 2.29$ and $51.62 \pm 3.36 \mu \mathrm{M}$, 
A

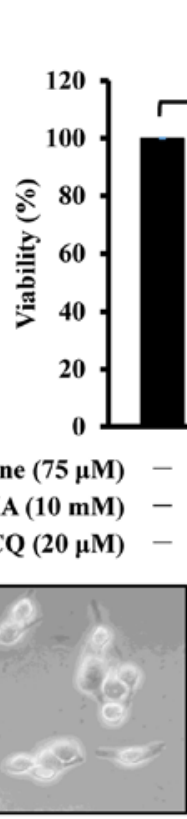

Control

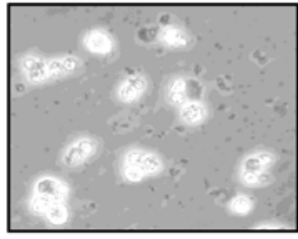

Pterostilbene (75 $\mu \mathrm{M})$

3-MA (10 mM) -

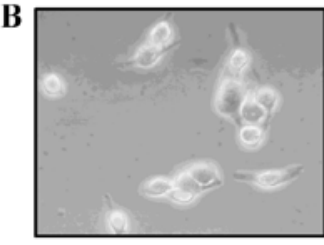

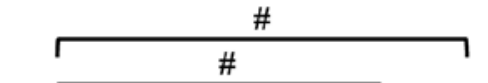

$\sim$

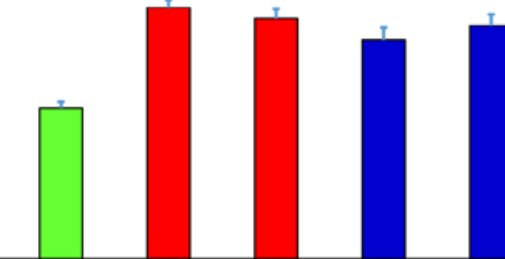

Pterostilbene $(75 \mu \mathrm{M}) \quad-$

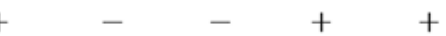

$-\quad+$

$-$

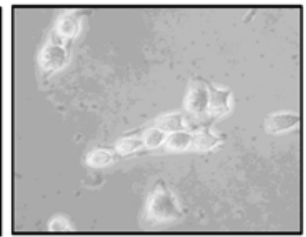

3-MA (10 mM)

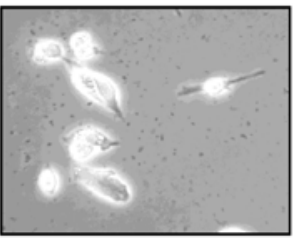

3-MA (10 mM)

+ Pterostilbene $(75 \mu \mathrm{M})$

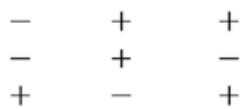

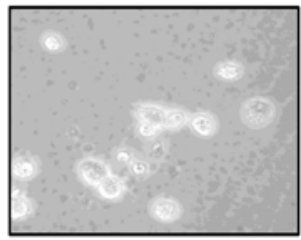

CQ $(20 \mu M)$

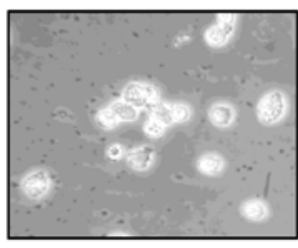

CQ $(20 \mu \mathrm{M})$

+ Pterostilbene (75 $\mu \mathrm{M})$
C

Control

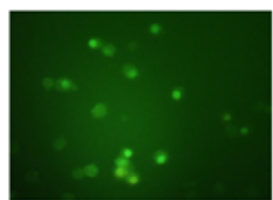

3-MA (10 mM)

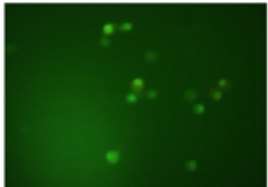

Pterostilbene (75 $\mu \mathrm{M})$

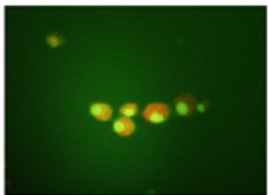

CQ $(20 \mu M)$

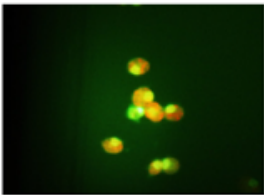

Pterostilbene $(75 \mu \mathrm{M})$

+ 3-MA (10 mM)

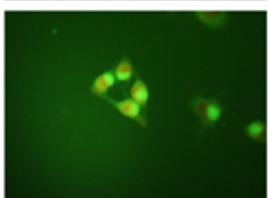

Pterostilbene $(75 \mu \mathrm{M})$

$+\mathrm{CQ}(20 \mu \mathrm{M})$

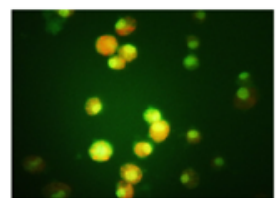

Figure 5. Effects of the autophagy inhibitors 3-MA and CQ on the pterostilbene-induced autophagy of CAR cells. Cells were exposed to $75 \mu \mathrm{M}$ pterostilbene for $24 \mathrm{~h}$ following pretreatment with $10 \mathrm{mM}$ 3-MA and $20 \mu \mathrm{M}$ CQ for $1 \mathrm{~h}$. (A) Cell viability was detected using an MTT assay. Values represent the mean \pm standard deviation of three independent experiments. ${ }^{*} \mathrm{P}<0.05$ vs. untreated control; ${ }^{*} \mathrm{P}<0.05$ vs. cells treated with pterostilbene alone. (B) The autophagic characteristic of CAR cells were observed by phase-contrast microscopy (magnification, $\mathrm{x} 400$ ). (C) Acidic vesicular organelles indicating cell autophagy were detected using staining with acridine orange and assessed using a fluorescence microscope. Each representative image was taken from three independent experiments (magnification, x400). 3-MA, 3-methyladenine; CQ, chloroquine.

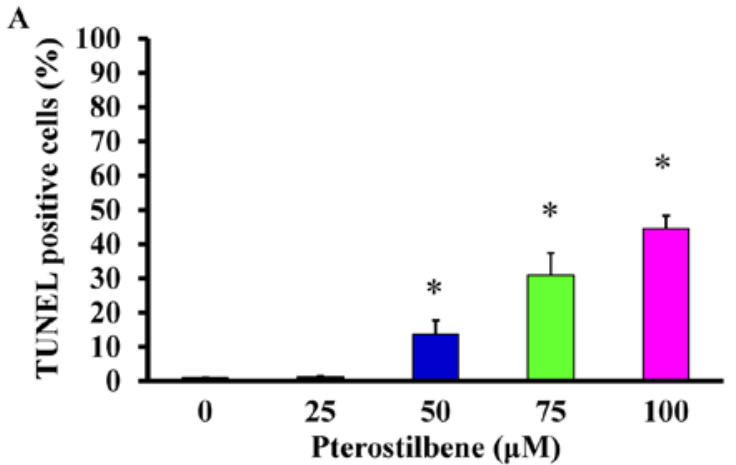

B

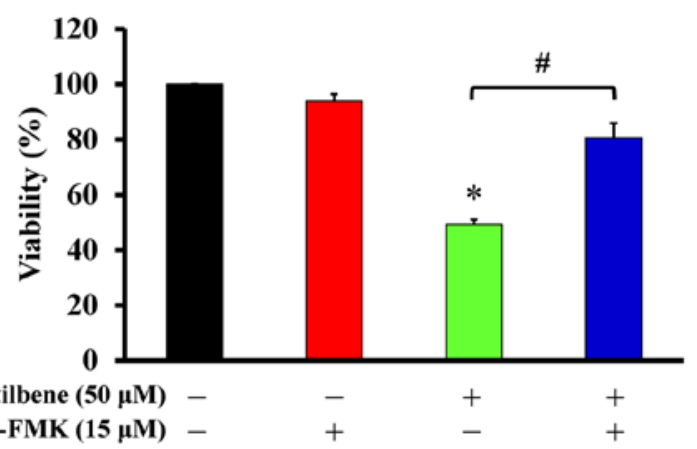

Figure 6. Effects of pterostilbene on apoptosis and the caspase-dependent signaling of CAR cells. Cells were incubated with $0,25,50,75$ or $100 \mu \mathrm{M}$ pterostilbene for $48 \mathrm{~h}$ following pre-incubation with or without $15 \mu \mathrm{M}$ Z-VAD-FMK for $1 \mathrm{~h}$. (A) TUNEL-positive cells were detected using a commercial kit and analyzed using flow cytometry. (B) Cell viability was measured using the MTT assay. Values represent the mean \pm standard deviation of three independent experiments. ${ }^{\prime} \mathrm{P}<0.05$ vs. untreated control; ${ }^{\#} \mathrm{P}<0.05$ vs. exposure to pterostilbene alone. Z-VAD-FMK, carbobenzoxyvalyl-alanyl-aspartyl fluoromethyl ketone; TUNEL, terminal deoxynucleotidyl transferase-mediated d-UTP nick end labeling.

respectively (51). However, the present study indicated that the $\mathrm{IC}_{50}$ values of pterostilbene were $78.26 \pm 4.33,48.04 \pm 3.68$ and $20.65 \pm 4.88 \mu \mathrm{M}$ in CAR cells following 24,48 and $72 \mathrm{~h}$ incubation, respectively. This indicates that pterostilbene exhibits greater effects at lower concentrations than resveratrol. These results suggest that pterostilbene exhibits greater anticancer effects than resveratrol.

Previous studies have demonstrated that pterostilbene is an effective antioxidant with anticancer potential, which induces cell death and exhibits anti-metastatic actions $(16,30,32,34,37)$. 
A

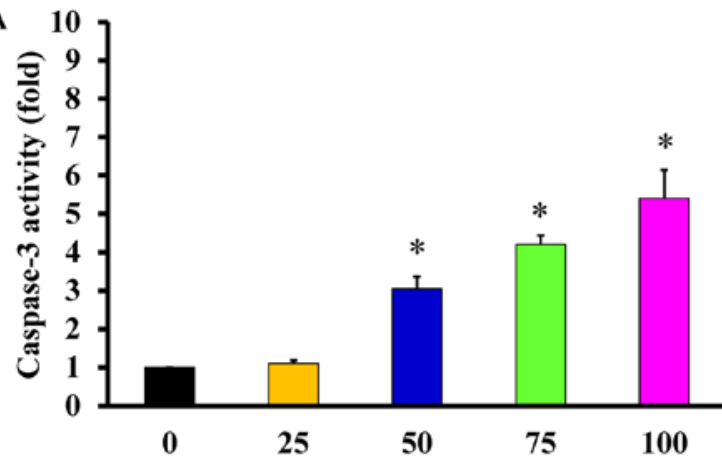

B

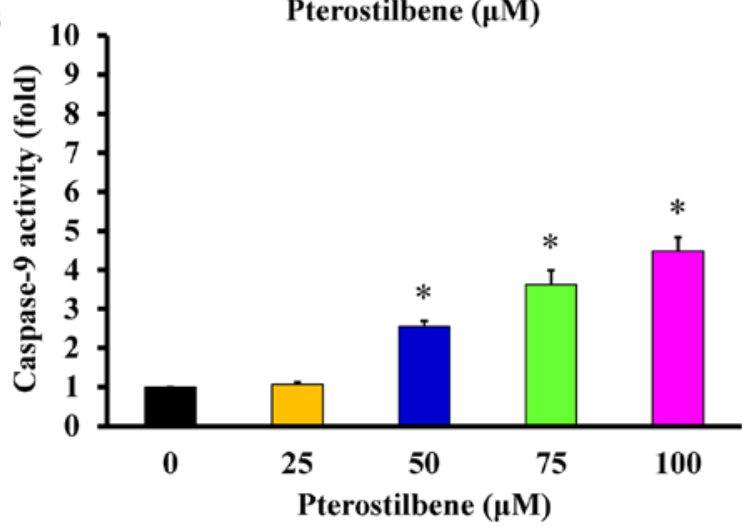

C

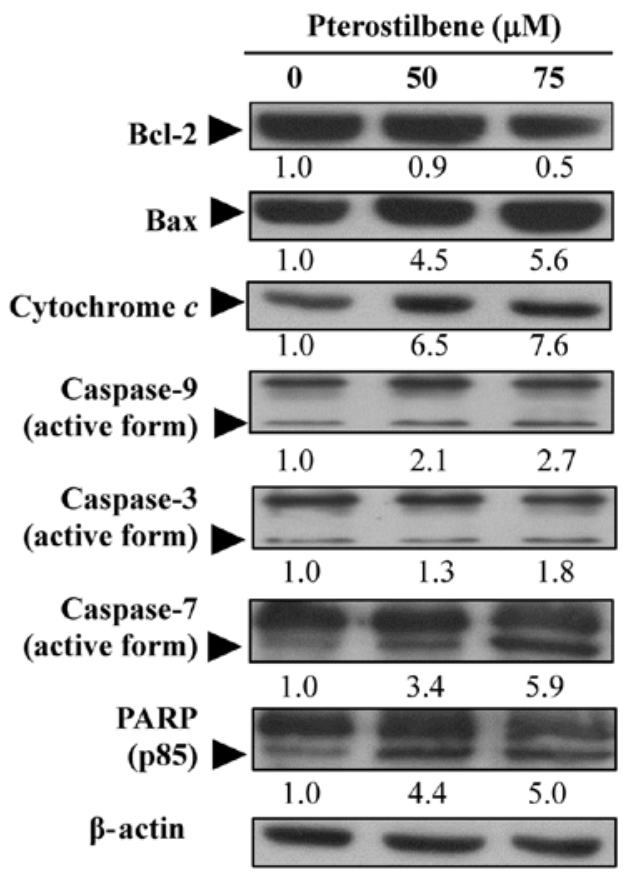

Figure 7. Effects of pterostilbene on the mitochondria-dependent apoptotic signaling of CAR cells. Cells were incubated with $0,25,50,75$ or $100 \mu \mathrm{M}$ pterostilbene for $48 \mathrm{~h}$, and whole-cell lysates were then harvested. (A) Caspase-3 and (B) -9 activities were determined using a colorimetric assay. Values represent the mean \pm standard deviation of three independent experiments. ${ }^{~} \mathrm{P}<0.05$ vs. untreated control. (C) Cell fractions were probed with anti-Bcl-2, anti-Bax, anti-cytochrome $c$, anti-caspase-9, anti-caspase-3, anti-caspase-7 and anti-PARP antibodies and assessed via western blotting. Representative images were taken from three independent experiments. PARP, Poly (ADP-ribose) polymerase.

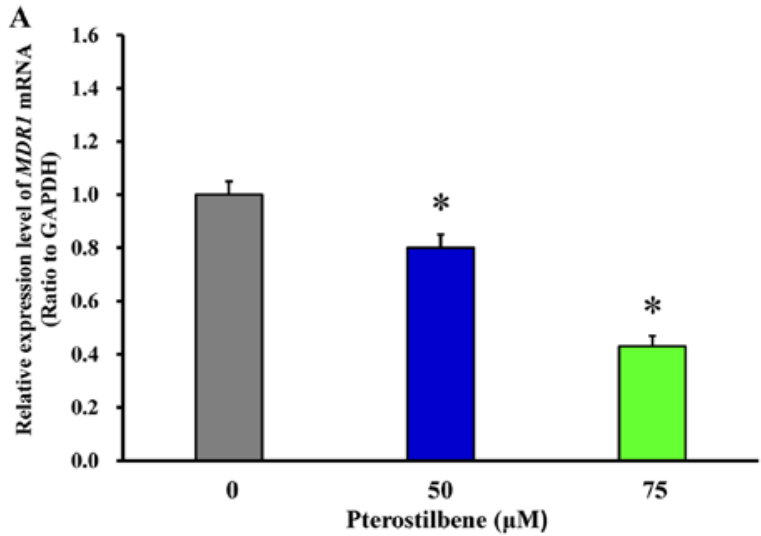

B

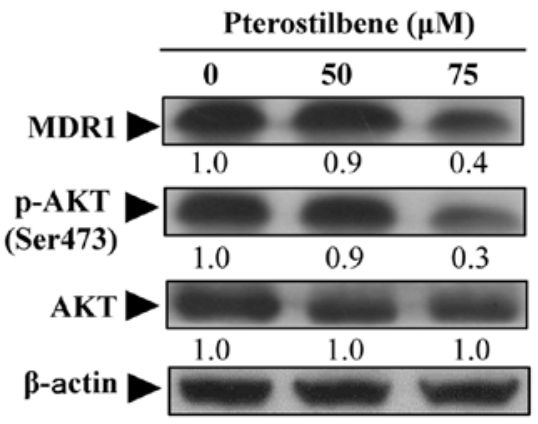

Figure 8. Effects of pterostilbene on MDR1 expression and AKT signaling in CAR cells. Cells were treated with or without 50 and $75 \mu \mathrm{M}$ pterostilbene for $24 \mathrm{~h}$, harvested and underwent RT-qPCR analysis and western blot analysis, respectively. (A) Total RNA was extracted, and RT-qPCR analysis was performed to determine MDR1 mRNA expression. Values represent the mean \pm standard deviation of three independent experiments. ${ }^{*}<0.05$ vs. untreated control. (B) Western blotting was performed to measure MDR1, p-AKT on Ser473 and total AKT protein expression. Representative images were from three independent experiments. MDR1, multidrug resistance protein 1; AKT, protein kinase B; p-, phosphorylated.

Furthermore, it has been demonstrated that pterostilbene triggers apoptosis in pancreatic cancer (MIA PaCa-2 and PANC-1) $(20,21)$, breast cancer (MDA-MB-468, MCF-7 and MDA-MB-231) $(18,19)$, lung cancer (LCC, PC9, NCI-H460, SK-MES-1 and A549) (22-24,29), osteosarcoma (SOSP-9607) (62), prostate cancer (PC-3 and LNCaP) $(25,26)$, leukemia (Jurkat, Hut-78, HL60, MOLT4 and K562) (37-40), colon cancer (Colo 205, HCT116 and HT29) (27-29), bladder cancer (T24) (30), hepatocellular carcinoma (HepG2) $(35,36)$, gastric carcinoma (AGS) (31) and oral cancer (SAS and OECM-1) (32) cell lines. In addition, pterostilbene exhibits autophagic effects in various types of cancer $(29,30,38,39,42)$. The results of the present study demonstrated that treatment with 5-100 $\mu \mathrm{M}$ pterostilbene significantly inhibited the viability and confluence of CAR cells. These results are in accordance with those of a study by Ko et al (32), which demonstrated that pterostilbene inhibits the proliferation of human oral cancer SAS and OECM-1 cells. 


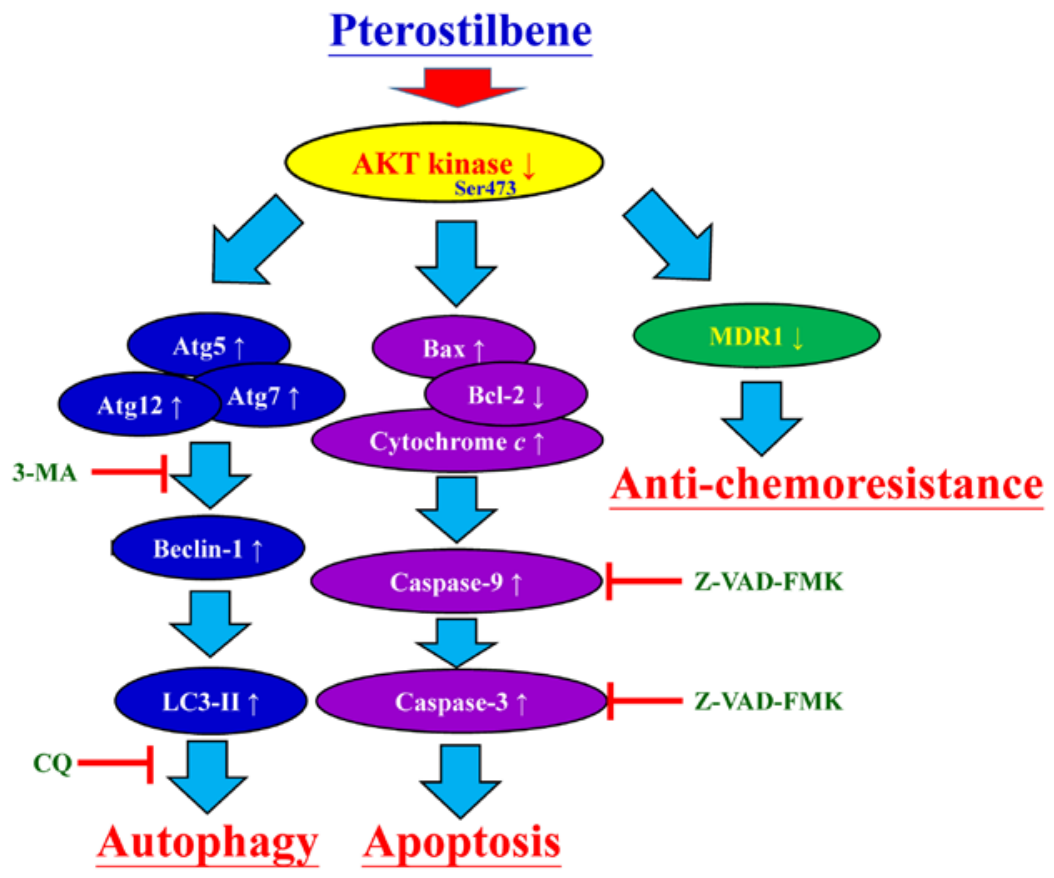

Figure 9. Proposed schematic representation of plausible molecular signaling in pterostilbene-induced autophagic and apoptotic machineries of cisplatinresistant human oral cancer CAR cells. 3-MA, 3-methyladenine; CQ, chloroquine. MDR1, multidrug resistance protein 1; AKT, protein kinase B; Atg, autophagy-related gene; LC3, light chain 3; Z-VAD-FMK, carbobenzoxyvalyl-alanyl-aspartyl fluoromethyl ketone.

In the present study, $\mathrm{AO}$ and $\mathrm{MDC}$ staining indicated that pterostilbene stimulated the formation of autophagic vesicles in CAR cells. LysoTracker Red staining also detected lysosome activity following treatment with pterostilbene. LC3 expression is a characteristic of autophagic vesicle membrane in early autophagosome formation (63). The results of the present study indicated that pterostilbene increased the mRNA expression of the autophagic genes LC3-II and Atg12 and the protein expression of the autophagy-associated proteins Atg5, Atg7, Atg12, Beclin-1 and LC3-II in CAR cells. To determine the autophagic effect on CAR cells, the autophagy inhibitors 3-MA and CQ were used to determine whether pterostilbene induces autophagy. The results demonstrated that they protected against the pterostilbene-induced decrease in cell viability. The results of the present study are in accordance with those of a previous study (32), which demonstrated that pterostilbene stimulated the formation AVOs and autophagic vacuoles and increased the expression of LC3-II and Beclin-1 protein in human oral cancer SAS and OECM-1 cells. It is important to note that autophagy was detected following $24 \mathrm{~h}$ treatment with pterostilbene in the present study; however, no dramatic activation of caspase-3 was observed following exposure to pterostilbene for $24 \mathrm{~h}$. These results imply that pterostilbene-induced autophagy occurs prior to CAR cell apoptosis.

The present study also demonstrated that pterostilbene induced apoptosis by performing an TUNEL assay, which demonstrated that pterostilbene significantly increased the number of TUNEL-positive cells. Pterostilbene-triggered apoptosis was confirmed by the pan-caspase inhibitor Z-VAD-FMK, which reversed the reduction of cellular viability in the pterostilbene-treated cells. A significant increase in the activity of caspases-3 and -9 and the expression of their active forms were observed in CAR cells following pterostilbene treatment. Hsiao et al (64) reported that pterostilbene induced mitochondria-dependent apoptosis in human leukemia HL60 cells. Furthermore, Schneider et al (24) demonstrated that pterostilbene induced mitochondria-dependent apoptosis in human lung cancer NCI-H460 and SK-MES-1 cells. The results of the present study suggest that pterostilbene provokes caspasedependent mitochondria-derived apoptosis in CAR cells.

MDR1, also known as p-glycoprotein, is encoded by the ATP Binding Cassette Subfamily B Member 1 gene. It is a subunit of the ATP-dependent transporter and is involved in the development of resistance of tumor cells to chemotherapeutic agents $(65,66)$. It has been demonstrated that the inhibition of AKT effectively stimulates the sensitivity of chemotherapeutic agents by inhibiting AKT-mediated MDRI gene expression (66). Previous studies have demonstrated that MDR1 overexpression is involved in the development of cisplatin-resistance in CAR cells $(44,50,66)$. The results of the present study demonstrated that pterostilbene inhibited MDR1 mRNA and protein expression by downregulating the expression of phosphorylated AKT on Ser473 in CAR cells.

In conclusion, the results of the present study support the proposition that pterostilbene-induced autophagic and apoptotic CAR cell death may be involved in AKT-mediated MDR1 suppression. Therefore, the present study indicates that pterostilbene may be a promising candidate as an oral anticancer drug or an adjuvant to chemotherapeutic reagents and may be developed as a potential therapeutic agent to treat oral cancer in the future.

\section{Acknowledgements}

We thank Mr. Meng-Jou Liao (Tekon Scientific Corp., Taiwan), Mr. Chin-Chen Lin (Tekon Scientific Corp., Taiwan) and Mr. Chang-Wei Li (AllBio Science Incorporated, Taiwan) for their excellent technique and equipment support. 


\section{Funding}

The present study was supported by China Medical University Hospital (Taichung, Taiwan; grant no. DMR-107-123) and partly by the Ministry of Science and Technology, Taiwan (grant no. MOST 105-2320-B-039-033-).

\section{Availability of data and materials}

The data sets generated during the study are available from the corresponding author on reasonable request.

\section{Authors' contributions}

HPC, CCL and JSY conceived and designed the experiments. JHC, YNJ, JWT and HYC performed the experiments. CCL, FJT and JSY analyzed the data. HPC, CCL and JSY wrote and modified the paper. All authors read and approved the final manuscript.

\section{Ethics approval and consent to participate}

Not applicable.

\section{Consent for publication}

Not applicable.

\section{Competing interests}

The authors declare that they have no competing interests.

\section{References}

1. Tsai SC, Huang SF, Chiang JH, Chen YF, Huang CC, Tsai MH, Tsai FJ, Kao MC and Yang JS: The differential regulation of microRNAs is associated with oral cancer. Oncol Rep 38: 1613-1620, 2017.

2. Kawakita D, Lee YA, Li Q, Chen Y, Chen CJ, Hsu WL, Lou PJ, Zhu C, Pan J, Shen H, et al: Impact of oral hygiene on head and neck cancer risk in a Chinese population. Head Neck 39: 2549-2557, 2017

3. Ministry of Health and Welfare: Republic of China (Taiwan). https://www.mohw.gov.tw/cp-3425-33347-2.html. 2017.

4. Chiang SL, Velmurugan BK, Chung CM, Lin SH, Wang ZH, Hua CH, Tsai MH, Kuo TM, Yeh KT, Chang PY, et al: Preventive effect of celecoxib use against cancer progression and occurrence of oral squamous cell carcinoma. Sci Rep 7: 6235, 2017.

5. Macha MA, Rachagani S, Qazi AK, Jahan R, Gupta S, Patel A, Seshacharyulu P, Lin C, Li S, Wang S, et al: Afatinib radiosensitizes head and neck squamous cell carcinoma cells by targeting cancer stem cells. Oncotarget 8: 20961-20973, 2017.

6. Rapidis A, Sarlis N, Lefebvre JL and Kies M: Docetaxel in the treatment of squamous cell carcinoma of the head and neck. Ther Clin Risk Manag 4: 865-886, 2008.

7. Bauman J, Langer C, Quon H, Algazy K, Lin A, Desai A, Mutale $\mathrm{F}$ and Weiss $\mathrm{J}$ : Induction chemotherapy with cetuximab, carboplatin and paclitaxel for the treatment of locally advanced squamous cell carcinoma of the head and neck. Exp Ther Med 5: $1247-1253,2013$.

8. Torres-Bugarín O, Ventura-Aguilar A, Zamora-Perez A, Gómez-Meda BC, Ramos-Ibarra ML, Morgan-Villela G, Gutiérrez-Franco A and Zúñiga-González G: Evaluation of cisplatin +5 -FU, carboplatin $+5-\mathrm{FU}$, and ifosfamide + epirubicine regimens using the micronuclei test and nuclear abnormalities in the buccal mucosa. Mutat Res 539: 177-186, 2003.

9. Passiglia F, Listì A, Castiglia M, Perez A, Rizzo S, Bazan V and Russo A: EGFR inhibition in NSCLC: New findings.... and opened questions? Crit Rev Oncol Hematol 112: 126-135, 2017.
10. Housman G, Byler S, Heerboth S, Lapinska K, Longacre M, Snyder N and Sarkar S: Drug resistance in cancer: An overview. Cancers (Basel) 6: 1769-1792, 2014.

11. Zahreddine $\mathrm{H}$ and Borden KL: Mechanisms and insights into drug resistance in cancer. Front Pharmacol 4: 28, 2013.

12. Wang YY, Chen YK, Hsu YL, Chiu WC, Tsai CH, Hu SC, Hsieh PW and Yuan SF: Synthetic $\beta$-nitrostyrene derivative CYT-Rx20 as inhibitor of oral cancer cell proliferation and tumor growth through glutathione suppression and reactive oxygen species induction. Head Neck 39: 1055-1064, 2017.

13. McCormack D and McFadden D: A review of pterostilbene antioxidant activity and disease modification. Oxid Med Cell Longev 2013: 575482, 2013.

14. Dvorakova M and Landa P: Anti-inflammatory activity of natural stilbenoids: A review. Pharmacol Res 124: 126-145, 2017.

15. McCormack D and McFadden D: Pterostilbene and cancer: Current review. J Surg Res 173: e53-e61, 2012.

16. Xue EX, Lin JP, Zhang Y, Sheng SR, Liu HX, Zhou YL and $\mathrm{Xu} \mathrm{H}$ : Pterostilbene inhibits inflammation and ROS production in chondrocytes by activating Nrf2 pathway. Oncotarget 8: 41988-42000, 2017.

17. Bhakkiyalakshmi E, Sireesh D, Sakthivadivel M, Sivasubramanian S, Gunasekaran P and Ramkumar KM: Antihyperlipidemic and anti-peroxidative role of pterostilbene via Nrf2 signaling in experimental diabetes. Eur J Pharmacol 777: 9-16, 2016.

18. Wakimoto R, Ono M, Takeshima M, Higuchi T and Nakano S: Differential anticancer activity of pterostilbene against three subtypes of human breast cancer cells. Anticancer Res 37: 6153$6159,2017$.

19. Nikhil K, Sharan S, Chakraborty A, Bodipati N, Krishna Peddinti R and Roy P: Role of isothiocyanate conjugate of pterostilbene on the inhibition of MCF-7 cell proliferation and tumor growth in Ehrlich ascitic cell induced tumor bearing mice. Exp Cell Res 320: 311-328, 2014.

20. Kostin SF, McDonald DE and McFadden DW: Inhibitory effects of (-)-epigallocatechin-3-gallate and pterostilbene on pancreatic cancer growth in vitro. J Surg Res 177: 255-262, 2012.

21. Mannal PW, Alosi JA, Schneider JG, McDonald DE and McFadden DW: Pterostilbene inhibits pancreatic cancer in vitro. J Gastrointest Surg 14: 873-879, 2010.

22. Ma Z, Yang Y, Di S, Feng X, Liu D, Jiang S, Hu W, Qin Z, Li Y, Lv J, et al: Pterostilbene exerts anticancer activity on non-smallcell lung cancer via activating endoplasmic reticulum stress. Sci Rep 7: 8091, 2017.

23. Wang YJ, Lin JF, Cheng LH, Chang WT, Kao YH, Chang MM, Wang BJ and Cheng HC: Pterostilbene prevents AKT-ERK axismediated polymerization of surface fibronectin on suspended lung cancer cells independently of apoptosis and suppresses metastasis. J Hematol Oncol 10: 72, 2017.

24. Schneider JG, Alosi JA, McDonald DE and McFadden DW: Pterostilbene inhibits lung cancer through induction of apoptosis. J Surg Res 161: 18-22, 2010.

25. Nikhil K, Sharan S, Chakraborty A and Roy P: Pterostilbeneisothiocyanate conjugate suppresses growth of prostate cancer cells irrespective of androgen receptor status. PLoS One 9: e93335, 2014

26. Lin VC, Tsai YC, Lin JN, Fan LL, Pan MH, Ho CT, Wu JY and Way TD: Activation of AMPK by pterostilbene suppresses lipogenesis and cell-cycle progression in $\mathrm{p} 53$ positive and negative human prostate cancer cells. J Agric Food Chem 60: 6399-6407, 2012.

27. Sun Y, Wu X, Cai X, Song M, Zheng J, Pan C, Qiu P, Zhang L, Zhou S, Tang $\mathrm{Z}$, et al: Identification of pinostilbene as a major colonic metabolite of pterostilbene and its inhibitory effects on colon cancer cells. Mol Nutr Food Res 60: 1924-1932, 2016.

28. Tolba MF and Abdel-Rahman SZ: Pterostilbine, an active component of blueberries, sensitizes colon cancer cells to 5-fluorouracil cytotoxicity. Sci Rep 5: 15239, 2015.

29. Mena S, Rodríguez ML, Ponsoda X, Estrela JM, Jäättela M and Ortega AL: Pterostilbene-induced tumor cytotoxicity: A lysosomal membrane permeabilization-dependent mechanism. PLoS One 7: e44524, 2012.

30. Chen RJ, Ho CT and Wang YJ: Pterostilbene induces autophagy and apoptosis in sensitive and chemoresistant human bladder cancer cells. Mol Nutr Food Res 54: 1819-1832, 2010.

31. Pan MH, Chang YH, Badmaev V, Nagabhushanam K and Ho CT: Pterostilbene induces apoptosis and cell cycle arrest in human gastric carcinoma cells. J Agric Food Chem 55: 7777-7785, 2007. 
32. Ko CP, Lin CW, Chen MK, Yang SF, Chiou HL and Hsieh MJ: Pterostilbene induce autophagy on human oral cancer cells through modulation of Akt and mitogen-activated protein kinase pathway. Oral Oncol 51: 593-601, 2015.

33. Bundela S, Sharma A and Bisen PS: Potential compounds for oral cancer treatment: Resveratrol, nimbolide, lovastatin, bortezomib, vorinostat, berberine, pterostilbene, deguelin, andrographolide, and colchicine. PLoS One 10: e0141719, 2015.

34. Lin CW, Chou YE, Chiou HL, Chen MK, Yang WE, Hsieh MJ and Yang SF: Pterostilbene suppresses oral cancer cell invasion by inhibiting MMP-2 expression. Expert Opin Ther Targets 18 $1109-1120,2014$

35. Guo L, Tan K, Wang $\mathrm{H}$ and Zhang X: Pterostilbene inhibits hepatocellular carcinoma through $\mathrm{p} 53 / \mathrm{SOD} 2 / \mathrm{ROS}$-mediated mitochondrial apoptosis. Oncol Rep 36: 3233-3240, 2016.

36. Lombardi G, Vannini S, Blasi F, Marcotullio MC, Dominici L, Villarini M, Cossignani L and Moretti M: In vitro safety/protection assessment of resveratrol and pterostilbene in a human hepatoma cell line (HepG2). Nat Prod Commun 10: 1403-1408, 2015.

37. Chang G, Xiao W, Xu Z, Yu D, Li B, Zhang Y, Sun X, Xie Y Chang S, Gao L, et al: Pterostilbene induces cell apoptosis and cell cycle arrest in T-cell leukemia/lymphoma by suppressing the ERK1/2 pathway. BioMed Res Int 2017: 9872073, 2017.

38. Siedlecka-Kroplewska K, Jozwik A, Boguslawski W, Wozniak M, Zauszkiewicz-Pawlak A, Spodnik JH, Rychlowski M, Kmiec Z: Pterostilbene induces accumulation of autophagic vacuoles followed by cell death in HL60 human leukemia cells. J Physiol Pharmacol 64: 545-556, 2013.

39. Siedlecka-Kroplewska K, Jozwik A, Kaszubowska L, Kowalczyk A and Boguslawski W: Pterostilbene induces cell cycle arrest and apoptosis in MOLT4 human leukemia cells. Folia Histochem Cytobiol 50: 574-580, 2012.

40. Roslie H, Chan KM, Rajab NF, Velu SS, Kadir SA, Bunyamin I, Weber JF, Thomas NF, Majeed AB, Myatt G, et al: 3,5-Dibenzyloxy-4'-hydroxystilbene induces early caspase-9 activation during apoptosis in human K562 chronic myelogenous leukemia cells. J Toxicol Sci 37: 13-21, 2012.

41. Wang Y, Ding L, Wang X, Zhang J, Han W, Feng L, Sun J, Jin H and Wang XJ: Pterostilbene simultaneously induces apoptosis, cell cycle arrest and cyto-protective autophagy in breast cancer cells. Am J Transl Res 4: 44-51, 2012.

42. Chakraborty A, Bodipati N, Demonacos MK, Peddinti R, Ghosh K and Roy P: Long term induction by pterostilbene results in autophagy and cellular differentiation in MCF-7 cells via ROS dependent pathway. Mol Cell Endocrinol 355: 25-40, 2012.

43. Gosepath EM, Eckstein N, Hamacher A, Servan K, von Jonquieres G, Lage H, Györffy B, Royer HD and Kassack MU: Acquired cisplatin resistance in the head-neck cancer cell line Cal27 is associated with decreased DKK1 expression and can partially be reversed by overexpression of DKK1. Int J Cancer 123 2013-2019, 2008

44. Chang PY, Peng SF, Lee CY, Lu CC, Tsai SC, Shieh TM, Wu TS Tu MG, Chen MY and Yang JS: Curcumin-loaded nanoparticles induce apoptotic cell death through regulation of the function of MDR1 and reactive oxygen species in cisplatin-resistant CAR human oral cancer cells. Int J Oncol 43: 1141-1150, 2013.

45. Lu CC, Huang BR, Liao PJ and Yen GC: Ursolic acid triggers nonprogrammed death (necrosis) in human glioblastoma multiforme DBTRG-05MG cells through MPT pore opening and ATP decline. Mol Nutr Food Res 58: 2146-2156, 2014.

46. Huang WW, Chiu YJ, Fan MJ, Lu HF, Yeh HF, Li KH, Chen PY, Chung JG and Yang JS: Kaempferol induced apoptosis via endoplasmic reticulum stress and mitochondria-dependent pathway in human osteosarcoma U-2 OS cells. Mol Nutr Food Res 54: $1585-1595,2010$

47. Sun JM, Yang LN, Xu H, Chang B, Wang HY and Yang G: Inhibition of Aurora A promotes chemosensitivity via inducing cell cycle arrest and apoptosis in cervical cancer cells. Am J Cancer Res 5: 1133-1145, 2015.

48. Gelles JD and Chipuk JE: Robust high-throughput kinetic analysis of apoptosis with real-time high-content live-cell imaging. Cell Death Dis 7: e2493, 2016.

49. Lee MR, Lin C, Lu CC, Kuo SC, Tsao JW, Juan YN, Chiu HY, Lee FY, Yang JS and Tsai FJ: YC-1 induces G0/G1phase arrest and mitochondria-dependent apoptosis in cisplatin-resistant human oral cancer CAR cells. Biomedicine (Taipei) 7: 12, 2017.

50. Hsieh MT, Chen HP, Lu CC, Chiang JH, Wu TS, Kuo DH, Huang LJ, Kuo SC and Yang JS: The novel pterostilbene derivative ANK-199 induces autophagic cell death through regulating PI3 kinase class III/beclin 1/Atg related proteins in cisplatin resistant CAR human oral cancer cells. Int J Oncol 45: 782-794, 2014.
51. Chang CH, Lee CY, Lu CC, Tsai FJ, Hsu YM, Tsao JW, Juan YN, Chiu HY, Yang JS and Wang CC: Resveratrol-induced autophagy and apoptosis in cisplatin-resistant human oral cancer CAR cells: A key role of AMPK and Akt/mTOR signaling. Int J Oncol 50: 873-882, 2017

52. Livak KJ and Schmittgen TD: Analysis of relative gene expression data using real-time quantitative PCR and the 2(-Delta Delta C(T)) method. Methods 25: 402-408, 2001.

53. Chiang JH, Yang JS, Lu CC, Hour MJ, Chang SJ, Lee TH and Chung JG: Newly synthesized quinazolinone HMJ-38 suppresses angiogenetic responses and triggers human umbilical vein endothelial cell apoptosis through p53-modulated Fas/death receptor signaling. Toxicol Appl Pharmacol 269: 150-162, 2013.

54. Ma YS, Weng SW, Lin MW, Lu CC, Chiang JH, Yang JS, Lai KC, Lin JP, Tang NY, Lin JG, et al: Antitumor effects of emodin on LS1034 human colon cancer cells in vitro and in vivo: Roles of apoptotic cell death and LS1034 tumor xenografts model. Food Chem Toxicol 50: 1271-1278, 2012.

55. Lu CC, Yang JS, Chiang JH, Hour MJ, Lin KL, Lee TH and Chung JG: Cell death caused by quinazolinone HMJ-38 challenge in oral carcinoma CAL 27 cells: Dissections of endoplasmic reticulum stress, mitochondrial dysfunction and tumor xenografts. Biochim Biophys Acta 1840: 2310-2320, 2014.

56. Tsai HY, Ho CT and Chen YK: Biological actions and molecular effects of resveratrol, pterostilbene, and 3'-hydroxypterostilbene. J Food Drug Anal 25: 134-147, 2017.

57. Traversi G, Fiore M, Leone S, Basso E, Di Muzio E, Polticelli F, Degrassi F and Cozzi R: Resveratrol and its methoxy-derivatives as modulators of DNA damage induced by ionising radiation. Mutagenesis 31: 433-441, 2016.

58. Lin HS, Yue BD and Ho PC: Determination of pterostilbene in rat plasma by a simple HPLC-UV method and its application in pre-clinical pharmacokinetic study. Biomed Chromatogr 23: 1308-1315, 2009

59. Lin HS and Ho PC: Preclinical pharmacokinetic evaluation of resveratrol trimethyl ether in sprague-dawley rats: The impacts of aqueous solubility, dose escalation, food and repeated dosing on oral bioavailability. J Pharm Sci 100: 4491-4500, 2011.

60. Yeo SC, Ho PC and Lin HS: Pharmacokinetics of pterostilbene in Sprague-Dawley rats: The impacts of aqueous solubility, fasting, dose escalation, and dosing route on bioavailability. Mol Nutr Food Res 57: 1015-1025, 2013.

61. Asensi M, Medina I, Ortega A, Carretero J, Baño MC, Obrador E and Estrela JM: Inhibition of cancer growth by resveratrol is related to its low bioavailability. Free Radic Biol Med 33: 387-398, 2002.

62. Liu Y, Wang L, Wu Y, Lv C, Li X, Cao X, Yang M, Feng D and Luo Z: Pterostilbene exerts antitumor activity against human osteosarcoma cells by inhibiting the JAK2/STAT3 signaling pathway. Toxicology 304: 120-131, 2013.

63. Yang JS, Lu CC, Kuo SC, Hsu YM, Tsai SC, Chen SY, Chen YT, Lin YJ, Huang YC, Chen CJ, et al: Autophagy and its link to type II diabetes mellitus. Biomedicine (Taipei) 7: 8, 2017.

64. Hsiao PC, Chou YE, Tan P, Lee WJ, Yang SF, Chow JM, Chen HY, Lin CH, Lee LM and Chien MH: Pterostilbene simultaneously induced G0/G1-phase arrest and MAPK-mediated mitochondrial-derived apoptosis in human acute myeloid leukemia cell lines. PLoS One 9: e105342, 2014.

65. DavoudiZ,Akbarzadeh A,Rahmatiyamchi M,Movassaghpour AA, Alipour M, Nejati-Koshki K, Sadeghi Z, Dariushnejad H and Zarghami N: Molecular target therapy of AKT and NF-kB signaling pathways and multidrug resistance by specific cell penetrating inhibitor peptides in HL-60 cells. Asian Pac J Cancer Prev 15: 4353-4358, 2014.

66. Yuan CH, Horng CT, Lee CF, Chiang NN, Tsai FJ, Lu CC, Chiang JH, Hsu YM, Yang JS and Chen FA: Epigallocatechin gallate sensitizes cisplatin-resistant oral cancer CAR cell apoptosis and autophagy through stimulating AKT/STAT3 pathway and suppressing multidrug resistance 1 signaling. Environ Toxicol 32: $845-855,2017$

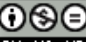

This work is licensed under a Creative Commons Attribution-NonCommercial-NoDerivatives 4.0 International (CC BY-NC-ND 4.0) License. 